\section{Commentary: Cardiac surgery and coronavirus disease 2019 (COVID-19): Lessons learned in Italy - the hard way}

\author{
Andra E. Duncan, MD, MS
}

Coronavirus disease 2019 (COVID-19) was declared a pandemic by the World Health Organization on March 11, $2020^{1}$ — only a few months after a cluster of cases of "viral pneumonia" was identified in Wuhan, Hubei Province. Since then, COVID-19 has taken its toll worldwide. Italy was the first European nation to be affected by COVID-19. ${ }^{2}$ By mid-March, the COVID-19 pandemic had severely hit the country and was responsible for about $50 \%$ of excess deaths. ${ }^{3}$ While Italy was in the midst of this outbreak, the world observed the challenges of this pandemic and the health care crisis that ensued. Many lessons could be learned.

Fattouch and colleagues ${ }^{4}$ describe a COVID-19 outbreak at the Maria Eleonara Hospital in Palmero, Italy. The southern district of Palmero had been partially spared from the pandemic at this time, so this Hospital was designated a "COVID-19-free" hub, serving as a primary hospital for emergent cardiovascular procedures. The subsequent COVID-19 outbreak at this hospital provides an important learning opportunity where contributing factors and effectiveness of interventions can be observed.

One lesson to be gleaned is that standard screening procedures for COVID-19, including fever, cough, dyspnea, recent travel, and exposure to a patient positive for COVID-19, were not effective in preventing an outbreak. COVID-19 infection occurred in 36\% (20/55) of hospitalized patients, and 3 patients $(15 \%)$ died. Twelve health care workers were also infected. The source of infection-whether presymptomatic patients were admitted for surgery or if health

\footnotetext{
From the Department of Cardiothoracic Anesthesiology and Outcomes Research, Cleveland Clinic, Cleveland, Ohio.

Disclosures: The author reported no conflicts of interest.

The Journal policy requires editors and reviewers to disclose conflicts of interest and to decline handling or reviewing manuscripts for which they may have a conflict of interest. The editors and reviewers of this article have no conflicts of interest.

Received for publication Oct 23, 2020; revisions received Oct 23, 2020; accepted for publication Oct 26, 2020; available ahead of print Nov 6, 2020.

Address for reprints: Andra E. Duncan, MD, MS, Department of Cardiothoracic Anesthesiology, Cleveland Clinic, 9500 Euclid Ave - J4, Cleveland, OH 44195 (E-mail: duncana@ccf.org).

J Thorac Cardiovasc Surg 2022;163:1095

$0022-5223 / \$ 36.00$

Copyright (c) 2020 by The American Association for Thoracic Surgery

https://doi.org/10.1016/j.jtcvs.2020.10.096
}

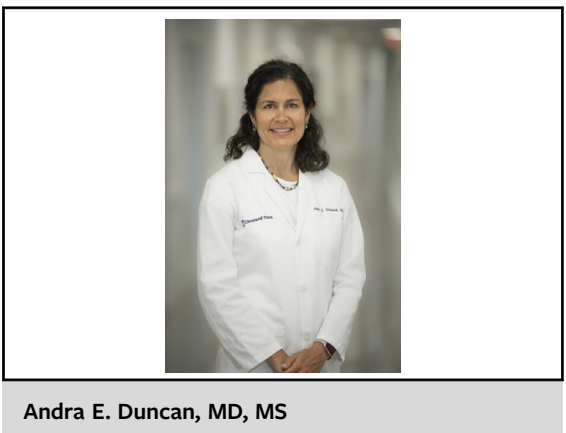

CENTRAL MESSAGE

Improved screening procedures,

frequent testing, and hospital

policy changes reduced risk for a

second COVID-19 outbreak in

patients after cardiac surgery.

care workers were the source-is unclear. The lesson is that more stringent guidelines are needed. Another lesson lies in the hospital's actions: cardiac surgery was suspended until patients and health care workers were tested. Then, stricter screening measures and changes in hospital policy were implemented. Consequently, no additional COVID-19 cases occurred. New hospital policy measures included screening with nasopharyngeal swabs, a dedicated "bubble" in which patients remain until test results were known, and frequent testing of health care workers. Sadly, another lesson was that postoperative mortality was excessive during the outbreak, perhaps because older patients with significant comorbidities were affected, or, perhaps because postoperative patients are especially vulnerable. Interestingly, less than $40 \%$ of patients had other COVID-19 symptoms, possibly because fever or shortness of breath were disguised as common postoperative complications.

This major hospital in Italy learned these lessons the hard way. We have the opportunity to learn from their experience, which, by far, is the preferred — and easier way.

\section{References}

1. Cucinotta D, Vanelli M. WHO declares COVID-19 a pandemic. Acta Biomed 2020;91:157-60.

2. Indolfi C, Spaccarotella C. The outbreak of COVID-19 in Italy: fighting the pandemic. JACC Case Rep. 2020;2:1414-8.

3. Alicandro G, Remuzzi G, La Vecchia C. Italy's first wave of the COVID-19 pandemic has ended: no excess mortality in May, 2020. Lancet. 2020;396:e27-8.

4. Fattouch K, Corrao S, Augugliaro E, Minacapelli A, Nogara A, Zambelli G, et al Cardiac surgery outcomes in patients with coronavirus disease 2019 (COVID-19): a case-series report. J Thorac Cardiovasc Surg. 2022;163:1085-92.e3. 